\title{
MICROWAVE ASSISTED ECO FRIENDLY SYNTHESIS OF 2H- PYRIDO [1, 2-a] PYRIMIDINE-2-ONE
}

\author{
Sharulatha $\mathrm{V}^{1}$, Indumathi $\mathbf{U}^{2}$, Priyadharshini $\mathrm{S}^{3}$ \\ ${ }^{I}$ Assistant professor, Avinashilingam Institute for Home Science and Higher Education for Women, Coimbatore \\ ${ }^{2}$ Research Scholar, Avinashilingam Institute for Home Science and Higher Education for Women, Coimbatore \\ ${ }^{3}$ Research Scholar Avinashilingam Institute for Home Science and Higher Education for Women, Coimbatore
}

\begin{abstract}
Pyrido primidines are important class of heterocylic compounds because of their use in medicinal and agro chemistry as scaffolds for active agents such as antiviral, antiulcer, antimalarial, antifungal and herbicidal agents. Herein we report the synthesis of $2 H$ pyrido[1,2-a]pyrimidine-2-ones by the reaction of itaconic acid with 2-amino pyridine in tow steps under classical and microwave technology.
\end{abstract}

Keywords: microwave synthesis 2H-pyrido [1, 2-a] pyrimidine-2-one - ***

\section{INTRODUCTION}

The organic reactions under microwave irradiation are more advantageous over the conventional methods, owing to shortening of reaction time, mild temperature conditions, and good-to-high yield[1], eco-friendliness and non-use of expensive reagents [2]. The pyrimidine framework is an important structural moiety present in various biologically active molecules including DNA and RNA[3]. Benzo- and hetero-fused pyrimidines are known to exhibit promising antiviral, antiabacterial, anti-AIDS, and antinociceptive activities. The relevance of fused pyrimidines as antiplatelet and antithrombotic drugs has been firmly established by clinical trials[4]. One such fused pyrimidine core with nitrogen at ring junction is pyrido[1,2-a]pyrimidine.

Pyrido[1,2-a]pyrimidine-4-one derivatives, were found to be aldols reductase (ALR2) inhibitor [5], human leukocyta elastase inhibitor [6], antibacterial agents [7], potential antiviral agents [8]. In light of the important biological properties of Pyrido[1,2-a]pyrimidines, the development of simple and convenient methodology for the synthesis of this structural motif represents an interesting area of research in synthetic organic and medicinal chemistry.

Generally, the pyridopyrimidine ring is constructed by condensation based on the amidine fragment of 2aminopyridine or its derivatives with various acylating and alkylating agents [9].Most of the reported methods involve the use high temperatures and pressure and use of acid catalysts with low yields and formation of significant amount of by products.

Herein we report the convenient and versatile synthesis of 2H-pyrido[1,2-a]pyrimidine-2-one with high yields and purity by the reaction of 2-amno pyridine with the inexpensive reagent itaconic acid under conventional and microwave heating. PTSA(p-toluene sulfonic acid) was used as cylcizing agent, Since it makes the reaction process convenient, cost effective and environmentally benign[10].

\section{RESULTS AND DISCUSSION}

The title compound was synthesized by a convenient two step reaction, outlined in scheme -1.

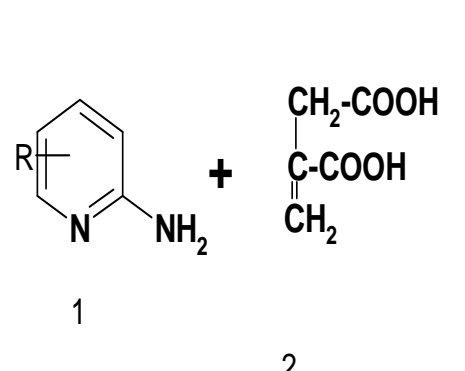

2

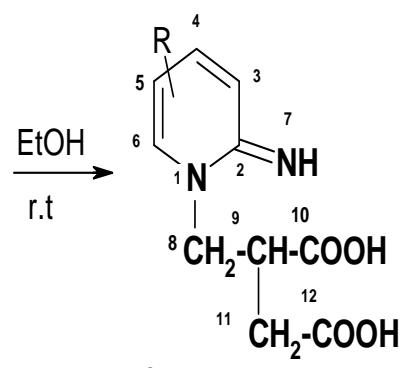

$R=H(3 a), 4 \mathrm{Me}(3 b), 6 \mathrm{Me}(3 c)$
$R 1=H,(4 a) 6 \mathrm{Me}(4 b), 8 \mathrm{Me}(4 \mathrm{c})$<smiles>O=c1ccn2ccccc2n1</smiles>

4

Scheme - 1

The 2-amino pyridine was stirred with itaconic acid with alcohol in the first step to provide compound 3 (imino $1,2(\mathrm{H})$ pyridine itaconic acid) as white solid. Recrystallisation of the 2- imino $1,2(\mathrm{H})$ pyridine itaconic acid(3) yielded white crystals with $95 \%$.Then imino $1,2(\mathrm{H})$ pyridine itaconic acid was heated with catalytic amounts of p-toluene sulfonic acid in alcohol to yield compound $2 \mathrm{H}$ pyrido[1,2-a]pyrimidine-2-one(4) as white solid. Again 
recrystallization with alcohol provided white crystals with $82 \%$ yield.

Lelle Vasvari-Debreczy[11] reported the cyclization of 2-(2pyridylaminomethylene)succinates in ethanolic sodium ethoxide. But the succinates gave equilibrium mixture of pyridopyrimidines and dihydropyyrolone a dimer at room temperature and at elevated temperature a mixture of products were obtained. But in our case the cyclization of imino 1,2(H) pyridine itaconic acid proceeded smoothly with the higher yield of pyridopyrimidine and formation of by products was found to be lesser. The reactions were also carried out by microwave heating. A comparison of conventional method vs microwave heating were summarized in the following table.

Table -1: Comparison of Conventional Heating vs Microwave heating of the synthesized compounds

\begin{tabular}{|c|c|c|c|c|c|c|c|c|c|}
\hline \multirow[t]{2}{*}{ Compounds } & \multicolumn{2}{|c|}{$\begin{array}{l}\text { Room } \\
\text { temperature }\end{array}$} & \multicolumn{2}{|c|}{ Microwave heating } & \multirow[t]{2}{*}{ Compounds } & \multicolumn{2}{|c|}{$\begin{array}{l}\text { Conventional } \\
\text { heating }\end{array}$} & \multicolumn{2}{|c|}{$\begin{array}{l}\text { Microwave } \\
\text { heating }\end{array}$} \\
\hline & $\begin{array}{l}\text { Yield } \\
(\%)\end{array}$ & $\begin{array}{l}\text { Time } \\
\text { (min) }\end{array}$ & $\begin{array}{l}\text { Yield } \\
(\%)\end{array}$ & $\begin{array}{l}\text { Time } \\
(\text { min) }\end{array}$ & & $\begin{array}{l}\text { Yield } \\
(\%)\end{array}$ & $\begin{array}{l}\text { Time } \\
\text { (min) }\end{array}$ & $\begin{array}{l}\text { Yield } \\
(\%)\end{array}$ & $\begin{array}{l}\text { Time } \\
\text { (min) }\end{array}$ \\
\hline $3 a$ & 96.8 & 45 & 97.2 & 1 & $4 a$ & 81 & 60 & 94.2 & 15 \\
\hline $3 \mathrm{~b}$ & 97.6 & 45 & 98.2 & 1 & $4 \mathrm{~b}$ & 82 & 60 & 95.1 & 15 \\
\hline $3 \mathrm{c}$ & 97.8 & 45 & 98.0 & 1 & $4 \mathrm{c}$ & 81 & 60 & 95.6 & 15 \\
\hline
\end{tabular}

In the formation of the 2-imino 1,2(H) pyridine itaconic acid reaction was completed at forty five minutes in conventional method and the time was drastically reduced to one minute in the case of microwave heating. In the case of cylisation time was reduced to fifteen minutes from one hour. The yield of the product was also found to be higher than the conventional method. The products were also obtained with greater purity in microwave heating.

The synthesized compounds were characterized by IR, ${ }^{1} \mathrm{H}$ and ${ }^{13} \mathrm{C}$ NMR spectral methods. 2- imino 1,2(H) pyridine itaconic acid 3a showed 3 sets of signals at $\delta 3.2,5.5-5.9$, $6.8-7.8$ for ${ }^{1} \mathrm{H}$ NMR(figure-1) The singlet at $\delta 3.2$ integrating to two protons was assigned to the $\mathrm{C}_{11}$ methylene protons. The doublet integrating at $\delta 5.5-5.9$ for two protons was assigned to $\mathrm{C}_{8}$ methylene protons. The protons integrating at $6.8-7.8$ confirmed aromatic ring. The IR spectrum exhibited absorption at $3382 \mathrm{~cm}^{-1}$ due to $\mathrm{O}-\mathrm{H}$ stretch of acids and absorption at $1662 \mathrm{~cm}^{-}$due to imines. The ${ }^{13} \mathrm{C}$ NMR(figure-2)spectrum showed, totally ten signals corresponding to 10 carbon atoms. The signals at $\delta 178$ and $\delta 175$ corresponded to two carboxyl groups, The signal at 4.7 $\delta$ was assigned to the $C_{9}$ methine carbon atom. The signal at $\delta 45$ corresponded to $C_{11}$ methylene carbon. The signal at $\delta$ 130 corresponded to $\mathrm{C}_{8}$ methylene carbon. The $\mathrm{C}=\mathrm{N}\left(\mathrm{C}_{2}\right)$ carbon appeared at $\delta 161$ and the aromatic carbon in the region of $\delta 141-145$. The elemental analysis of the compound revealed the presence of ten carbon atoms, twelve hydrogen atoms, two nitrogen and four oxygen atoms. Hence the formula was found to be $\mathrm{C}_{10} \mathrm{H}_{12} \mathrm{~N}_{2} \mathrm{O}_{4}$.

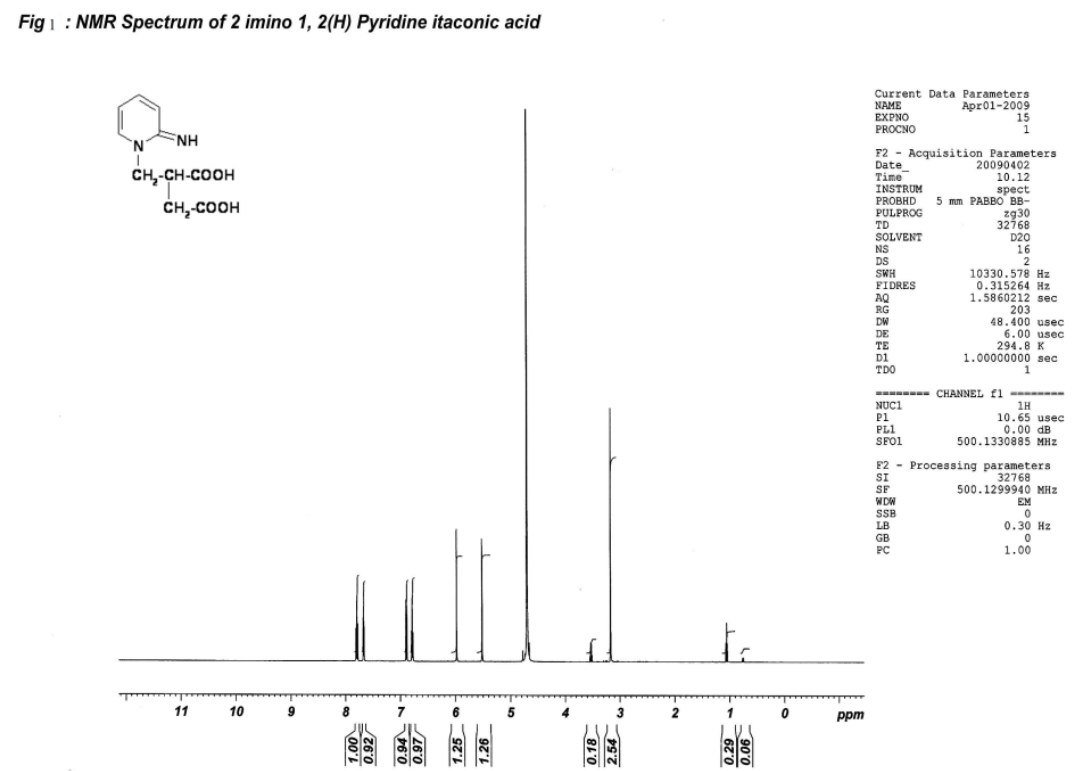

Fig-1 ${ }^{1} \mathrm{H}$ NMR of 2-imino1,2(H) pyridine itaconic acid 


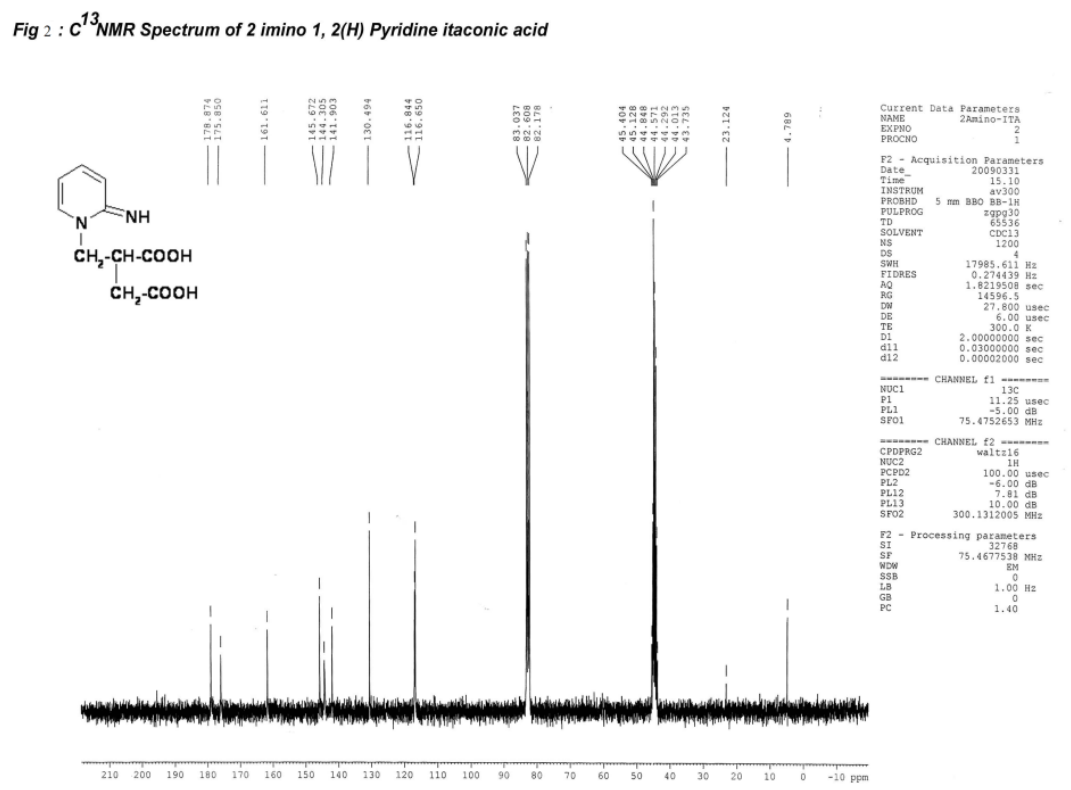

Fig-2 ${ }^{13} \mathrm{C}$ NMR of 2-imino1,2(H) pyridine itaconic acid

In the NMR spectrum of 2H-pyrido [1,2-a]pyrimidine-2-one (4c)totally four signals were observed for the four sets of protons. The signal observed at $\delta 1.84$ and $\delta 2.27$ indicated the presence of two methyl groups. The remaining four protons resonated at the aromatic region at $\delta 7.72$ and $\delta 7.6$. The deshielded proton at $6^{\text {th }}$ position will show absorbance at $\delta 9.0$ in 4-oxo isomer due to the anisotropy of the carbonyl group [12]. But in our case the resonance of proton at $6^{\text {th }}$ position was observed only at $\delta 7.72$ which confirmed the formation of 2-oxo isomer. ${ }^{13} \mathrm{C}$ spectrum accounted for nine carbons at $\delta 23 \delta 24 \delta 169 \delta 120 \delta 122 \delta 151 \delta 123 \delta 111 \delta$ 156.From the elemental analysis the percentage of carbon, hydrogen and nitrogen were found to be $68.50,5.6$ and16.0 respectively.

The mechanism of the reaction is illustrated in scheme-2. 2amino pyridine exists in two tautomeric forms. The ring nitrogen of 2-amino pyridine adds to the double bond of the methyl succinic acid, to give a carbanion intermediate. This carbonion abstracts a proton from the amino group to give the product $\mathbf{3}$. The product $\mathbf{3}$ gives $\mathbf{4}$ by the internal attack of the amino nitrogen on the carboxylic group with the elimination of water subsequently by the elimination of carbon dioxide.

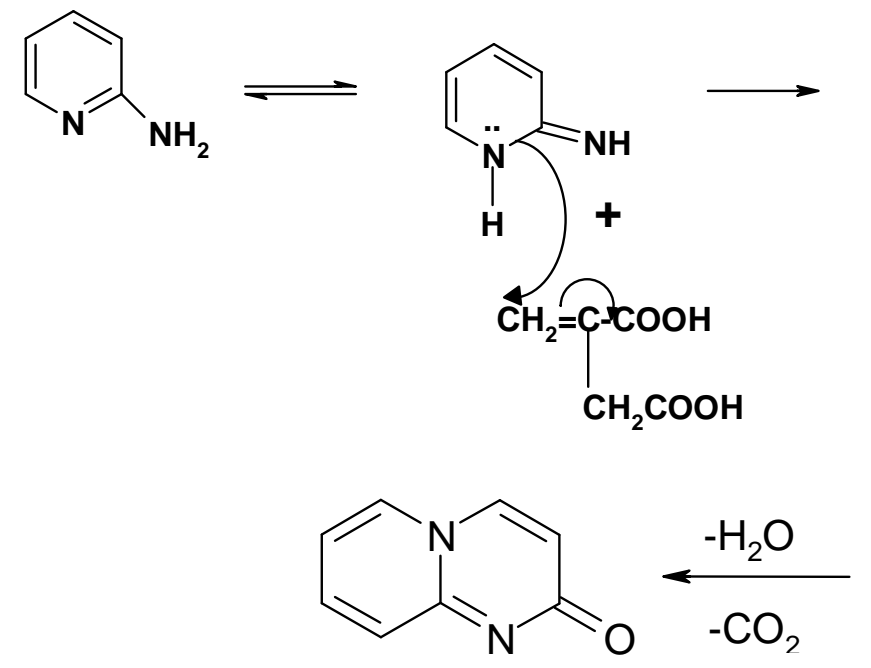

4

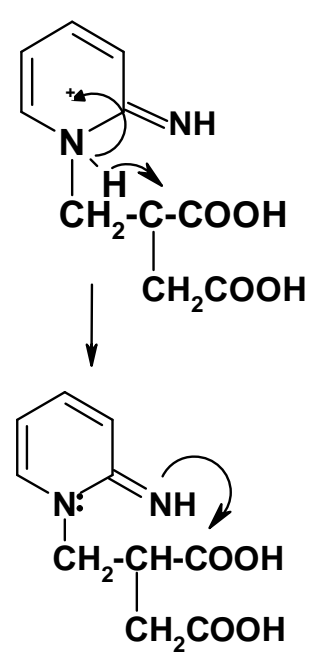

3

Scheme -2 Mechanism of the Reaction 


\section{EXPERIMENTAL}

\subsection{General}

Melting points were determined using Biochem melting point apparatus, and were uncorrected.The infrared (IR) spectra were recorded in $\mathrm{KBr}$ pellet technique on a PerkinElmer spectrophotometer. Absorption frequencies were quoted in reciprocal centimeter.

Nuclear Magnetic Resonance $\left({ }^{1} \mathrm{H}-\mathrm{NMR}\right)$ spectra were determined by Bruker modern $500 \mathrm{MHz}$ NMR instrument in $\mathrm{D}_{2} \mathrm{O}$ with tetra methyl silicane as the internal reference. Chemical shift were quoted in parts per million (ppm) (s =singlet; $\mathrm{d}=$ doublet; $\mathrm{t}=$ triplet and $\mathrm{m}=$ multiplet $)$.

Thin layer chromatography (TLC) was performed using glass plates coated with silica gel $\mathrm{G}$ to monitor and check the completion of each reaction.

Petroleum ether $\left(60-80^{\circ} \mathrm{C}\right)$; ethyl acetate; ethyl alcohol were used as the developing solvents. Spots were detected with iodine.The solvents and reagents used for the synthesis were of reagent grade and were purified by standard methods.

Microwave experiments were performed in domestic microwave oven LG model MS-1947C output 750 power watts. The reactions were conducted in a specially adapted cylindrical vensil vessel.

\subsubsection{Preparation of 2-imino 1,2(H) Pyridine}

\section{Itaconic Acid(3a)}

Dried itaconic acid (0.02mole) and 2-aminopyridine (0.01mole) were dissolved in ethyl alcohol separately. At room temperature one reactant was added to another drop wise and stirred well. The completion of the reaction was monitored by TLC. Recrystallisation with alcohol yielded pure compound. Melting point $=117^{\circ} \mathrm{C}$; Yield 94.4\%.CHN Analysis: Found: C, 53.27\%; H, 5.57\%; N, $12.07 \%$.

\subsubsection{Preparation of $2 \mathrm{H}$-pyrido[1,2-a] pyrimidine-2-}

\section{one $4 b$}

A mixture of 8-methyl 2- imino 1, 2(H) pyridine itaconic acid (0.1) and p-toluenesulphonic acid (0.1) in alcohol was heated to reflux on a steam bath, till the reaction was complete $(1 \mathrm{hr})$. After the completion of the reaction, the mixture was neutralized with $10 \%$ sodium hydroxide till the solution becomes neutral. The solution was concentrated under reduced pressure, and the solid was collected and purified recrystallisation from suitable solvent. Melting point $=119^{\circ} \mathrm{C}$; Yield $82 \%$.CHN Analysis: Found: C, 68.50; $\mathrm{H}, 5.6 ; \mathrm{N}, 16.0 \%$

\subsection{Microwave Oven}

\subsubsection{General Procedure}

Itaconic acid (0.02 mole) and (0.01 mole) of 2-amino pyridine were dissolved in ethyl alcohol and then irradiated at 800 watts in domestic microwave oven. The completion of the reaction was monitored by TLC.

A mixture of 2- imino $1,2(\mathrm{H})$ pyridine itaconic acid $(0.1)$ and p-toluenesulphonic acid (0.1) in alcohol was irradiated at 800 watts in domestic microwave oven. The completion of the reaction was monitored by TLC. After the completion of the reaction, the mixture was neutralized with $10 \%$ sodium hydroxide till the solution becomes neutral. The solution was concentrated under reduced pressure, and the solid was collected and purified recrystallisation from suitable solvent.

\section{CONCLUSIONS}

We have reported a simple and cost effective two step process of synthesis of $2 \mathrm{H}$-pyrido[1,2-a]pyrimidine-2-one from itaconic acid by microwave technology. The microwave assisted reaction was faster and yielded pure products.

\section{REFERENCES}

[1]. Sudhakar Reddy G., Harimohan, G and Lyengar,D.S., (1998); Indian J. Chem., 37B, 1167-1168

[2]. Caddick, S., (1995); Tetrahedron., 51, 10403-10432.

[3].Deevi Basavaiah and Tummanapalli Sathyanarayana,(2002); Tetrahedral Letters, 43,4301-4303.

[4].Raghunath B. Toche, Bhausaheb K Ghotekar, Muddassar A. Kazi, Dhananjay B. Kendre and Madhukar N. Jachak (2007);Tetrahedron. 63(34), 8157-8163.

[5].Concettina La Motta,Stefania Sartini, Laura Mugnaini, Francesca Simorini, Sabrina Taliani, Silvia Salerno, Anna Maria Marini, Federico Da Settimo, Antonio Lavecchia, Ettore Novellino, Miriam Cantore, Paola Failli, and Mario Ciuffi(2007); J. Med. Chem., 50, 4917-4927.

[6]. Hlasta D.J, AckermanJ.H, Mura A.Jand Desia R.C,(1995); USpatent5,378720.

[7]. Jonathan D.Rosen,Nadezha German and Robert J. Kerns(2009); Tetrahedral Letters50(7), 785-789

[8]. Ukrainets .V, Bereznyakova .N.L. and Turaibei I.A(2008);Chemistry of Heterocyclic Compounds.44(1),5061

[9]. Shidlovskii A. F, A. Yu. Sizov, L. N. Kuleshova, V. V. Nesterov, M. Yu. Antipin,. A. S Peregudov and N. D. Chkanikov(2000); Russian Chemical Bulletin 49(7),12571260

[10]. Ch Sanjeeva Reddy \& M Raghu (2008);Indian Journal of Chemistry 47B,1572-1577

[11]. Lelle Vasvari-Debreczy, lstvan Hermecz, Benjamin Podanyi, and Tunde Eros-Takacsy (1988); J.Chem.Soc. Perkin Trans I 2019 -2022

[12]. Hikmat N. Al-Jallo and Ibtisam A. Al-Biaty (1978); J.Hetrocyclic Chem., 15, 801 